\title{
Edyta Szymkowiak
}

(Uniwersytet im. Adama Mickiewicza w Poznaniu, Poznań - Polska)

\section{ЭТИЧЕСКАЯ ЦЕННОСТЬ ВСТРЕЧИ В СИСТЕМЕ ОБЩЕНИЯ ГЕРОЕВ КАК ПУТЬ К ВЫЯВАЕНИЮ ИСТИННОЙ НАТУРЫ ЧЕАОВЕКА (НА ОСНОВАНИИ РОМАНА ИАИОТ ФЕАОРА АОСТОЕВСКОГО)}

Кажется возможным выдвинуть тезис, об обреченности человека на непрерывный динамизм, вечный процесс становления, формирования, преображения, ведущий его к, обычно, призрачной цели. Стремление к „удовлетворению” цели или „конечной заботы”, как называет ее немецкий философ Пауль Тиллих, оказывается его онтологическим беспокойством и беспрестанным выхождением из себя1. Существу человечества принадлежит раскрытие на некую бесконечную действительность, хотя не всегда человек умеет ее назвать, определить, не всегда может узнать, какая сущность становится предметом этой заботы ${ }^{2}$. Бердяев пишет, что человек есть и единственное „дело” поставить на пути стремящегося к конечной цели, получается, что целью человека является другой человек. Отнюдь не имея в виду физической наружности, человек пытается проникнуть в его глубочайшую суть, разыскать прикрытую сложной структурой слоев эссенцию, составляющую основание его бытия.

Целью данной статьи будет попытка определения ценности идеи диалога-встречи, как основополагающей категории, ведущей к выявлению истинной природы человеческого бытия на основании романа Идиот Федора Достоевского. Предметом анализа послужит постепенно осуществляемая встреча на почве петербургской России двух главных героев - Мышкина и Рогожина - начиная с осмысления Мышкиным присутствия другого человека после выхода из гостиницы Весы, заканчивая на его приступе эпилепсии.

Отыскание другого лица является инициативой сближения, столь необходимого, ибо ведущего к самопознанию посредством

\footnotetext{
${ }^{1}$ Troska ostateczna, znak, symbol, symbol znakowy - dyskusja, http://www.staff.amu.edu.pl/ insfil/problemy-dyskusje/tom4/10d.pdf (10.10.2011).

2 Там же.

${ }^{3}$ Н.А. Бердяев, Миросозериание Достоевского, http://www.vehi.net/berdyaev/dostoevsky/ 02.html (10.10.2011).
} 
равноправного себе. „«Ты еси» устанавливает идею равноправного партнера и определяется как [...] емкий образец, регистрирующий идею преображения"4.

Аспект сосуществования, апробирован Мышкиным и оправдан актом полного осмысления присутствия другого человека, является непременным фактором переоценки его прежней позиции, а тем самым своего рода трансгрессии, ориентированной на выход за пределы собственной бытности, с целью „увидеть себя в тебе, в забытой идее партнерства вспомнить Целое, Истину" 5 .

„Да! Глаза их [Мышкина и Рогожина] встретились! и они посмотрели друг на друга"6. Князь, приведенный в действие силой человеческого взгляда, „ткет нить” взаимоотношений, постепенно приближаясь к своей цели. Такая форма визуального соприкосновения с другим человеком создает будто сильное магнетическое поле, притягивающее Мышкина к своему центру. Интенсивность его воздействия, кажется быть снабжаемой потоком удвоенной эфирной энергии, текущей по своеобразной линии соединяющей две самостоятельные и равноправные системы человеческого бытия. Расположение их центров на двух концах одной горизонтальной линии невольно приводит к конфронтации, где каждая из сторон будет принуждена к определению своей позиции.

А теперь, у дома, он стоял на другой стороне улицы, шагах в пятидесяти наискось, на противоположном тротуаре, скрестив руки, и ждал. Тут уже он был совсем на виду и, кажется, нарочно хотел быть на виду. Он стоял как обличитель и как судья (с. 242).

Итак, полярное противопоставление независимой единицы предопределяет коллизионный характер его позиции относительно Мышкина. Следовательно, приобретение такой позиции можно считать как выдвижение некого аргумента, примененного, будто в качестве демистификации своей оппозиционной стороны, но, одновременно, требующего обратного жеста - резонансного отзвука, отвечающего силой контраргумента.

Протяжение этой своего рода мобильной линии туда и обратно есть и стимул для установления невербальной, но все-таки активной, коммуникации, ориентированной на динамическое развитие

${ }^{4}$ H. Chałacińska-Wiertelak, Ikona i krzyż w antropologii prawostawnej, [в:] Fenomen daru, pod red. A. Grzegorczyk, A. Grada, R. Koschanego, Poznań 2004, c. 159.

${ }^{5}$ H. Chałacińska-Wiertelak, Театр ДостоеВского и размышления Павла Флоренского о русской иконе, „Studia Rossica Posnaniensia” 1993, nr 25, с. 21.

6 Ф.М. Достоевский, Идиот, Санкт-Петербург 2008, с. 242, В дальнейшем все цитаты по этому источнику - в скобках с указанием номера страницы. 
взаимозависимости, возникающей в пределах их воздействия. В свою очередь, нанесение в этом пространстве взаимоотношений граничных пунктов, определяемых двумя самостоятельными и равноправными центрами, дает гарантию непрерывного протекания производимой ними энергии, возобновляющейся каждый раз в момент достижения своей противоположной стороны. Следовательно, консистенция потока этой энергии, основывающейся на механизме обмена (контр) аргументами, подвергает сгущению, ибо каждый из аргументов, желая отбить своего предшественника, должен ответить хотя бы минимально увеличенной силой, что и предполагает динамическое усиление насыщенности потенции тех аргументов.

Такая линия эволюции невербальных, но все-таки коммуникативных, отношений вырисовывается после полного осмысления Мышкиным присутствия другого человека. Князь постепенно запутывается в горизонтальной сети взаимоотношений обусловливающей каждый его жест жестом другого. Невысказанное обвинение сразу сталкивается с возражением со стороны Мышкина в форме самооправдывающих контраргументов.

Ведь он [Мышкин] же сам хотел давеча взять его [Рогожина] за руку и пойти mуда вместе с ним? Ведь он сам же хотел завтра идти к нему и сказать, что он был у нее? Ведь отрекся же он сам от своего демона, еще идя туда, на половине дороги, когда радость наполнила его душу? (с. 242-243).

Заметно, что лихорадочное желание самоубеждения в правоте своих слов выражается Мышкиным в форме вопросов, постепенно усиливающих эмоциональный заряд скопившейся в них энергии. Каждый следующий вопрос ставит под сомнение авторитетность прежнего, тем самым прочность сложившегося мнения подвергается преломлению. Следовательно, процесс искусного построения целостного высказывания-контры переходит в свою противоположность, порождая бессвязный хаотический конгломерат мыслей, к тому же составленный по принципу прогрессивно увеличивающейся дистанции между своими компонентами („взять за руку” $\leftrightarrow$ „идти к нему” $\leftrightarrow$ "отрекся от своего демона”), что и имеет свое отображение в смысловом содержании тех мыслей (замечаем, что князь последовательно, будто „пространственно”, пытается удалить от своей интуитивной цели - другого человека). Обоснования этого явления следует искать в дефектном дескриптивном сознании ${ }^{7}$, подчиняющим себе человеческое бытие. В таком сознании происходит и процесс аксиологического суждения, классифицирования и категоризирования, применяющий критерий я 3 ы к о в о й экспрессии как

\footnotetext{
${ }^{7}$ Cм.: H. Brzoza, Między mitem, tragedia i apokalipsa, Toruń 1995, c. 187.
} 
высшей инстанции, служащей познанию действительности. Стабильность этой инстанции разрушается вместе с осмыслением ее порочности, выявляющейся в акте „семиотической дифференциации"8, ориентированной на раздвоение исходной сущности слова, а тем самым на диалогизацию его смысла в момент высказывания9.

Такое диалогизированное слово становится барьером для самого себя, ибо фокусируя внимание на своей внутрисистемной борьбе, отстраняет будто свою целенаправленную функцию - коммуникацию с другим. Отчужденная позиция слова невольно приводит К „проблеме 3 а к р ы т и я (заслонения) посредством говорения, определяющего целое человеческое отношение к миру.

Данное 3 а к р ы т и е нарушает процесс общения с другими, а также общения с самим собой ${ }^{10}$. Следовательно, акт (само)выражения (необязательно вербального, но все-таки задуманного), порожденный подражательной системой языковых средств, не отсылает здесь к действительности вне себя, ибо останавливается на самом себе, на своего рода стене построенной самим собой.

Таким образом, двусмысленные вопросы-контраргументы Мышкина могут быть направленными на свою внутрисистемную, а тем самым аб̆страктную реальность, заключающую их в сфере отвлеченной пустоты понятий. Парадоксально, чем больше жажда освобождения от своеобразного „смыслового небытия”, тем сложнее попытка осуществления ее.

Нечто такое, что видится само собой, но что трудно анализировать и рассказать, невозможно оправдать достаточными причинами, но что однако производит, несмотря на всю эту трудность и невозможность, совершенно цельное и неотразимое впечатление, невольно переходящее в полнейшее убеждение?... Убеждение - в чем? [...] Скажи же, если смеешь, в чем? - говорил он беспрерывно себе с упреком и с вызовом, - формулируй, осмелься выразить всю свою мысль, ясно, точно, без колебания! (с. 243).

Мышкин пытается пробиться через стену мыслей, затрудняющую ему доступ к глубинному смыслу диалога с другим. Каждая мысль, кажется грязнуть во лжи и представляется быть недостойной произнесения вслух. Как указывает Халина Бжоза, человеческая речь передает не только истину, но допускает игру, видимость, иллюзию, а даже притворство 11 . Панический страх искажения этой истины порождает колебания, сказывающиеся в бессилии предприятия конструктивных шагов, так как каждая форма выражения своего

${ }^{8}$ H. Chałacińska-Wiertelak, Театр Достоеßского..., ук. соч., с. 18.

${ }^{9}$ Там же.

${ }^{10}$ См.: H. Brzoza, Między mitem, tragedia i apokalipsa, ук. соч., с. 19.

11 Там же, с. 35. 
мнения непроизвольно есть и продукт субъективной оценки, нацеленной на предметный подход к другому. Нормирование другого человека, через вложение в пределы языковой оценочности ведет к лишению его фундамента индивидуальной субъектности, а тем самым подчинению закону абсолютной зависимости от собственного „ЯТ".

Мышкин больно ощущает это бессилие, обусловленное человеческим пристрастием к определению своего внутреннего мира словами, тем более, если объектом их анализа является другой человек. Потому и метод данного анализа должен принять измерение очищающего порыва, зиждущегося на своеобразной перетасовке акцентов ${ }^{12}$, предполагающей изменение перспективы из картезианского Я думаю в христианское Ты есть 13 .

Изворот этот является постольку существенным, поскольку допускает возможность открытия на ценности чужого слова (до сих пор угрожающего свободе собственного), а тем самым привести в движение потенциал собственной свободы посредством обмена мысли и действий с Другим ${ }^{14}$.

Осмысление князем данной необходимости становится импульсом к отвержению личных суждений и аргументов. „Да, я человек без сердца и трус!" (с. 243). Выход навстречу Другому есть и снесение барьера, загораживающего путь к непосредственному контакту. Итак, наблюдаем процесс о т к р ы в а н и я, происходящий как внутри Мышкина, так и в своеобразной физиономии Петербурга. „В то самое время, как князь подходил к дому, туча вдруг разверзлась и пролилась" (с. 244). Как замечаем, бурное состояние атмосферы Петербурга является адекватным беспокойному состоянию души князя. Неслучайным здесь кажется быть сам факт проявившегося ливня (прелюдия к переходу в измерение вертикальной перспективы) как своего рода „голоса” акватической стихии. О символике воды как очищающей энергии пишет Мирча Элиаде.

Вода предшествует любой форме и лежит в основе всякого творения, поддерживает его. Погружение в воду служит символом возвращения к предшествовавшему формам состоянию, символом полного обновления, очищения, второго рождения, ибо подобное погружение равнозначно разложению форм, возврату к недифференцированному, неразличимому способу пра-бытия, - тогда как выход из воды воспроизводит космогонический акт образования и внешнего обнаружения форм ${ }^{15}$.

12 Там же, с. 109.

13 Там же, с. 35.

14 Там же, с. 119.

${ }^{15}$ М. Элиаде, Трактат по истории религий, http://www.eliade.ru/voda-i-simvolikavod.html (12.10.2011). 
Следовательно, акт своеобразного крещения является и для Мышкина освобождением от ф о р м ы, пытающейся замкнуть в семантических пределах едва лишь внешний облик правды, лишенный своей внутренней сущности. Разрыв этой формы является разрывом гранищы, отделяющей князя от другого человека а тем самым попыткой восстановления целостности их неделимого начала.

„Мгновение спустя князь бросился вслед за ним на лестницу. Сердце его замерло" (с. 244). Если до сих пор оптика способности восприятия князем окружающего мира формировалась в структуре сетеобразных горизонтальных линий, в тот момент изменяет она свою плоскостную ориентацию. Существенным обстоятельством является здесь проявление с е р д ц а. Это с виду маловажное слово заключает в себе некую тайну необходимую для осмысления сущности перемены. Для открытия качества этой тайны следует проследить появление данного слова в анализированном фрагменте романа Идиот.

Уже в самом начале после выхода Мышкина из гостиницы „Весы" наблюдаем, что этот центральный орган кровеносной системы проявляет некую активность, подавляемую силой человеческой воли. „Он не хотел разрешать нахлынувших в его сердце и душу вопросов. «Что же, разве я виноват во всем этом?»" (с. 233). Сознательное отстранение голоса сердца в процессе своеобразного проникновения собственных чувств одновременно есть и подсознательный сигнал для князя, свидетельствующий о существовании некой второй плоскости, на плане которой вырисовывается будто мистериальный экскурс в неосмысленный вопрос. Следовательно, функция сердца замыкается к кругу чисто физиологической деятельности, редуцируя свой целостный потенциал к осязаемому ощущению выбиваемого ним ритма. „С е р д ц е его билось от беспокойного нетерпения" (с. 235). Пульсация этого органа есть и диапазон некой ширины, растягивающейся между сокращением сердща и его разжиманием, всегда ограниченной либо нижним, либо верхним пределом достигаемой позиции. Одновременно, сердце, выполняя функцию некого оперативного механизма, точит кровь, неся ответственность за ее беспрерывную циркуляцию по своеобразной сосудистой траектории внутри витального организма, в свою очередь спутанной непроницаемой сферой человеческой плоти. Итак, своего рода компрессия, заметная в процессе будто респирации сердца, резонирует с редуцированным масштабом кровеносной системы.

Действие так настроенной аппаратуры можно соотнести с движением земного времени. Континуум его протекания кажется быть изолированным самой невозможностью выхода из п л а в н о й 
структуры его границ в состояние застывшей вневременности. Парадоксально, сама конструкция этой структуры, несущая бремя вечного движения, основывается, как в случае кровообращения, так и истекания времени, на с виду далеко отходящей от аморфного процесса движения м а т е р и и.

Следовательно, внешняя субстанциональность названной материи оказывается иллюзорной, приняв во внимание непроизвольно навязанный будто сверху императив подчинения закону, управляемому категорией времени (итак, под покровом осязаемой прочности человеческой кожи „воплощается” динамическая деятельность сердца, независимая от воли самого человека).

Внешняя устойчивость, а также ощущение олицетворенной опоры в самом себе являются лишь маскировкой или „личиной"16 (в понимании Павла Флоренского), применяемой на период невысказанной борьбы с внутренним движением. Более того, в этой оболочковой форме тела можно усмотреть явную схожесть с вышеизложенным качеством слова, неспособного излить свою внутреннюю сущность, а тем самым закрытого в иллюзии правды.

В таком ракурсе метафорический акт замирания сердца Мышкина является символическим переломным моментом в продолжающимся конфликте. Не случайно это событие происходит сразу после первых шагов князя по лестнице, изображающей будто градационный процесс перехода из одного уровня в другой, следовательно, нарушающей горизонтальную ориентацию параллельной связи с другим человеком.

Расстройство внутри названной связи отражается именно на работоспособности сердца до сих пор отмеривающего ритм согласно горизонтальной перспективе истечения времени. Следует здесь еще раз привести вышеупомянутые слова. „Сердце его замерло. «Сейчас все р а 3 р е ш и т с я!»" (с. 244). Мнимое уничтожение органа, отвечающего за прочность и постоянность земной жизни, является побудительным стимулом, для развязки узлового вопроса о сущности человеческого бытия.

Произнесенные Мышкиным слова можно понимать как род своеобразной шифрограммы, кодирующей важную информацию, которой полное осмысление поможет довести князя к своей цели. Итак, глагол „разрешиться” по этимологическому словарю Фасмера происходит от древнерусского „ркшити”, обозначающего „развязать", но также... „отпустить грехи" 17.

16 П.А. Флоренский, Иконостас, http://www.vehi.net/florensky/ikonost.html (15.10.2011).

${ }_{17}$ М. Фасмер, Этимологический словарь русского языка, http://vasmer.narod.ru/p585.htm (25.10.2011). 
Момент выявления этой христианской перспективы является - что в контексте данных размышлений стоит особо подчеркнуть - моментом осмысления категории греха как своего рода предельного барьера, отделяющего от непосредственного контакта с другим человеком.

Французский философ, Поль Рикер, толкует сущность греха в категориях нарушения связи, следовательно, самоотчужденности, усматривая в его многозначном облике источник вопрошающего мышления ${ }^{18}$. Такая интерпретация служит ключом в нашей попытке осмысления некоего таинственного союза, установленного на базе грешной природы человеческого бытия.

Последовательность такую, хотя в обратном порядке, наблюдаем в образе жизни Мышкина. Застревая в генерированной словесной форме исследования и понимания окружающего мира, замечает он ее поверхностность и недостаточность. Не способен извлечь ее внутренней сути, князь балансирует в пространстве относительности, затемняющим какой-либо пункт отсчета.

Невозможность отыскания этого пункта ведет героя к ощущению затерянности, следовательно, алиенации, крайней степенью которой является осознание иллюзорности собственного существования, лишенного устойчивого упора, ибо укорененного в наружной почве временности и переходности. Однако, так ускоренный ход в конечном итоге ударяет в стену и, силой отброса, пятится, собирая по пути отбросы минувшей действительности, застывшие в прошлом, а тем самым, в воплощенной состоянии завершенности, поддающиеся целостному осмотру.

Так направленный ход отсылает к источнику - отправной точки, неосмысленной в момент уже ее движущегося начала, возобновленной в памяти в ретроспективном взгляде в прошлое. Согласно этой перспективе, князь обнаруживает величину, являющуюся разностью между первым и последним, чистым и загрязненным, в догадке - добрым и злым. Эту величину можно наименовать собственно г р ех о м. Вскрытая и осмысленная, является и она свидетельством существования состояния гармонического единства, расчлененного впоследствии на соринки условности и незавершенности. Таким образом, распознание изначального с о юз а происходит сквозь призму человеческого падения, парадоксально совершенного с целью вспомнить и полностью осмыслить этот союз.

Итак, Мышкин, обремененный сознанием греховности и распада человеческого бытия, предпринимает шаги к восстановлению

18 P. Ricoeur, Symbolika zła, przeł. S. Cichowicz, M. Ochab, Warszawa 1986, c. 11, 72. 
потерянной связи. Следуя за другим человеком по вертикально наклоненной плоскости лестницы, одновременно намечает себя „пятном" самоотверженности, для исполнения необходимой жертвы во имя попытки обновления первичного союза.

Эта лестница, как во всех давно строенных домах, была каменная, темная, узкая и вилась около толстого каменного столба (с. 244).

Конструкция того подъемного сооружения является и символическим местом прохода, тянущегося будто по силовой линии устойчивого упора в виде каменного столба. Охваченная всеобъемлющей темнотой, не позволяет доверять сенсорным органам познания, возлагая ответственность на тонкое чувство интуиции. Таким образом, эмпирический путь постижения земной действительности меняется в пользу трансцендентного, ибо внеопытного ощущения, выходящего за пределы феноменального восприятия явлений снаружи.

На первой забежной площадке в этом столбе оказалось углубление, вроде ниши, не более одного шага ширины и в полшага глубины. Человек, однако же, мог бы тут поместиться. Как ни было темно, но взбежав на площадку, князь тотчас же различил, что тут, в этой нише, прячется зачем-то ч е л о в е к (с. 244).

Наблюдаем, что посреди ряда доступных человеческим глазам образных фигур только одна из них выделяется резким интуитивным очертанием - фигура человека. Ее ощутимость сквозь занавес мнимой скрытности представляется как выведение некого таинственного движения и одновременно провокации, будучи призывом к конечной конфронтации.

Князю вдруг захотелось пройти мимо и не глядеть направо. Он ступил уже один шаг, но не выдержал и обернулся (с. 244).

Заметно, что центробежная сила, исходящая из вызывающего неясное подозрение места создает будто гравитационное поле, притягивающее князя к своему фокусу. Тем самым центр тяжести, размещенный внутри сознания Мышкина, выходит за пределы его единичности, локализируясь вне произвольного действия. Следовательно, князь оказывается в поле зависимости невнятной силы, способной к подчинению себе человеческого бытия. В свою очередь, сделанный Мышкиным поворот есть и акт полного открытия, столь существенный, ибо опускающий занавес, находящейся до сих пор в постоянном движении, земной непроницаемости человеческой природы.

Два давешние глаза, те же самые, вдруг встретились с его взглядом. Человек, таившийся в нише, тоже успел уже ступить из нее один шаг. Одну секунду оба стояли друг перед другом почти вплоть (с. 244). 
Визуальное соприкосновение, определяемое до сих пор сталкивающимся, диалогизированным в своем смысле, закрытым словом, покоряется безмолвию с целью очищения пространства встречи в пределах своего воздействия.

Безмолвие, освобожденное от пут диалектического, находящегося в постоянном движении аспекта слова есть и момент перехода в измерение вневременности, воплощающей самосознание т я ж е с т ь ю объективного познания. Таким образом, восстановление прежней горизонтальной ориентации меж двумя самостоятельными и равноправными центрами человеческого бытия происходит благодаря отвесному пересечению вертикальной перспективой, играющей здесь роль некого регулятора, нейтрализующего будто заряд накопленной меж ними (само)губительной энергии.

Проявление вертикальной перспективы можно прочитать как вмешательство Третьего ${ }^{19}$, по отношению к которому устанавливается порядок.

В рамках религиозного мировоззрения тем Третьим, в пределах диалогического контакта, с которым развивается понимание, будет Бог, знающий все тайны человеческого сердца ${ }^{20}$.

Итак, присутствие Бога детерминирует происходящий внутри названного контакта процесс взаимопонимания, так как дает возможность объективизации самосознания относительно высшей всеведущей инстанции. Является это особенно насущим если принять во внимание интенцию устанавливаемого контакта, а именно восстановление изначального союза, искаженного грехопадением. Не случайно произнесенные Мышкиным слова "сейчас все разрешится” предстают как предзнаменование этой ситуации, применяющей характер исповедального состояния, которого сущность выражается признанием в грехах.

Следует здесь выделить природу греха как особую форму вины, закладывающей, что человек, причиняя обиду другим, грешит перед Богом ${ }^{21}$. В таком ракурсе, изглаживается, замечаемый в прежних, пред-непосредственных контактах Мышкина с другим человеком, субъективный характер вины, маскированный внутри собственного сознания, а тем самым отдаленный от перспективы отпущения, следовательно, прощения грехов (несмотря на имманентное ощущение вины, отсутствует отнесение, к которому смог бы склониться

${ }^{19}$ CM.: D. Jewdokimow, Człowiek przemieniony. Fiodor M. Dostojewski wobec tradycji Kościota Wschodniego, Poznań 2009, c. 174.

20 Там же.

21 Там же. 
человек, что и противоречит самой сущности греха, будучи всегда провинностью перед кем-то и такого же отнесения требующей).

Как пишет Флоренский:

При всяком грехе требуемое им действие необходимо ставит грешника в определенные отношения к внешнему бытию, с его объективными свойствами и законами; и, ударяясь, в своем стремлении нарушить строй Божьего творения, о природу и о человечество, обыкновенный грешник тем самым имеет опорные точки одуматься и принести покаяние 22 .

Итак, целое Божьего творения, сказывающееся наиболее в возвышенной форме человека, принимая на себя бег разрушительного, греховного движения, одновременно становится особым пунктом опоры, по отношению к которому формируется качественное измерение греха, изменяющее оптику субъективной виновности в оптику провинности перед другим человеком, следовательно, перед Богом, в пределах которого совершится прощение.

Таким образом, сделанный Мышкиным поворот есть и своеобразное признание в грехах, следовательно покаяние, знаменующее „изменение образа мыслей, глубинной мысли нашего существа" 23. В свою очередь, признание это является и мерилом доверия, столь необходимого, ибо испытывающего воспринимаемую ценность вероисповедной достоверности другого 24 . Тем самым выбегающее к другому движение исповедного откровения становится стимулом для введения в действие потенциала провинности другого, в рамках которого должен совершиться аналогичный акт.

Вдруг князь схватил его за плечи повернул назад, к лестнице, ближе к свету; он яснее хотел видеть лицо (с. 244).

Выведение Мышкиным другого из углубления мрачной ниши есть и движение возникающего сближения, построенного формой линейного языка жеста, протянутого с центра зависимости другого в фокус эманации вертикальной величины, в поле воздействия которой отыскивается князь.

В свою очередь, извлечение лица другого к с в е т у знаменует "Духовное открытие через чувственность" 25 , инициируя момент его выявляющейся видимости в поле мышкинского зрения.

Итак, в симметрически сопоставленном выражении лица другого князь обнаруживает п о д о б и е, уловимое лишь в однозначном

\footnotetext{
22 П.А. Флоренский, Иконостас..., ук. соч.

23 Там же.

${ }^{24}$ CM.: J. Moskałyk, Ikoniczna rzeczywistość osoby i kościoła, Poznań 2007, c. 79.

${ }_{25}$ Cм.: P. Ricoeur, Egzystencja i hermeneutyka. Rozprawy o metodzie, przeł. J. Skoczylas, Warszawa 1975, с. 93, [цит. по:] Н. Brzoza, Między mitem..., ук. соч., с. 175.
} 
соответствии между его образным проявлением и содержательной сущностью26, неискаженной двусмысленностью речевой передачи, следовательно, выявляющее единообразие человеческой природы.

Более того, наблюдаем, что осмысление этого подобия вырисовывается будто на плане крестового сплетения, создаваемого горизонтальной линией (определяющей противоположные позиции двух центров человеческого бытия) и пересекающей ее осью симметрии вертикальной перспективы, приведшей их к такой же ориентации. Замечание это невольно отсылает к многоплановой символике креста, которого конструкция, основываясь на плане двух центробежных линий, назначающих четырехсторонний бег находящихся под воздействием взаимной поляризации радиусов, одновременно подчиняется закону центростремительного движения, спаивающего их в единстве и неделимости совместного начала.

Следовательно, смысловая геометрия креста, зиждущаяся на горизонтальном разделении подразумеваемого сосуществования сфер sacrum и profanum стремится к достижению равновесия, будучи основой идеи примирения и объединения отделенных друг от друга сторон 27.

Глаза Рогожина засверкали, бешеная улыбка исказила его лицо. Первая рука его поднялась, и что-то блеснуло в ней; князь не думал ее останавливать. Он помнил только, что, кажется крикнул: - Парфен, не верю!... (с. 244).

Итак, попытка убийства есть и признание в своей греховности, перевоплощающее внутреннее порожденную интенцию в акт обнаруженного действия.

В тот момент и выявляется иконный характер природы Мышкина. Принимая во внимание двухуровневое измерение греха, являющегося всегда провинностью, как перед человеком, так и перед Богом, обязательным становится факт вмешательства именно той высшей силы, проявляющей свое присутствие в покаянной природе человека. Таким образом, князь, „спаивая” в себе потенцию Божьего милосердия, необходимую для христианской перспективы отпущения грехов, и человеческую способность проявления вольной воли, строит прощальный акт самопожертвования во имя восстановления изначального союза.

Следует здесь подчеркнуть значимость произнесенных Мышкиным слов. В анализированном фрагменте романа Идиот являются

26 Там же.

${ }^{27}$ См.: H. Chałacińska-Wiertelak, Ставрогин - „сердиевина" романа Ф.М. Достоевского „Бесы", [в:] Культурный код В литературном произведении, Poznań 2002, с. 78-90. 
они первым непосредственным обращением к другому, приобретая тем самым статус Слова п е р в и ч н о г о. Это наблюдение невольно наводит на мысль о начале Евангелия от Иоанна, усматривающей источник и причину Слова в Боге, следовательно, придающей ему характер онтологической ценности, закладывающей основы не столько категории языка сколько самого человека, вызванного к жизни именно словами: „сотворим человека по образу Нашему [и] по подобию Нашему" (Быт. 1: 26). Как наблюдаем, ветхозаветное Слово предстает как своеобразное волокно, из которого строится искусно сотканная ткань, составляющая целое человеческой твари. Следовательно, созидательная сущность Слова, отождествляемая с творческой потенцией Бога, есть и некая детерминанта, определяющая строй человеческого бытия, но, одновременно, по семантическому смыслу, обусловливающая пределы его действия. Таким образом, несовершенность диалогизированного слова, служащего вакуумной преградой в коммуникационном пространстве, меняется в пользу Слова т в о р я щ е г о, закладывающего почву под единство и совместность природы человеческого бытия. Так понимаемое Слово останавливает бег греховного движения, ибо объединяет противоположные центра сознанием полноты и неделимости в органической связи человеческой плоти с Божьей натурой.

Князь отшатнулся от него и вдруг упал навзничь, прямо вниз по лестнице, с размаху ударившись затылком о каменную ступень. [...] Целая лужица крови около головы вселяла недоумение: сам ли человек расшибся или „был какой грех” (c. 245).

Итак, излияние этой жидкой ткани, до сих пор замкнутой во внутренней системе телесной непроницаемости, есть и исполнение необходимой жертвы, перевоплощающей процесс вечного движения в состояние застывшей божественной вневременности, являющейся М о м е н т о м испытания п о л н о т ы человеческо-Божьего существа. 